\title{
Bakanae of Rice: A Serious Disease in Punjab
}

\author{
Pooja Katoch*, Abhishek Katoch, Mahendra Paudel and Shristi Upreti \\ University Institute of Agricultural Sciences, Chandigarh University, \\ Gharuan, Mohali (Punjab)-140413, India \\ *Corresponding author
}

Keywords

Bakanae,

Rice, Fusarium moniliforme, Punjab and Haryana

Article Info

Accepted:

xx April 2019

Available Online:

xx May 2019

\section{A B S T R A C T}

Bakanae of rice cause by Fusarium moniliforme [sexual stage: Gibberella fujikuroi] is one of the important disease of rice occurring throughout rice (Oryza sativa L.) growing regions of the world. Bakanae disease also known as "Foolish seedling disease" is emerged as a significantly important disease in rice growing country in Asia. The word Bakanae is derived from the Japanese word which means "Foolish". The incidence of this disease was reported high from the part of Punjab, Haryana and Uttarakhand and responsible for $15 \%$ losses throughout the India. This disease is reported as both soil and seed borne and contains 15 forms of gibberellins out of 72 forms which make difficult to develop disease resistance varieties against this disease. The causative agent of bakane "Fusarium fujikuroi" produce secondary metabolites fusaric acids and gibberellic acid (GA) which result in the taller plantlet in the field with empty panicles. For the management of this disease various physical, chemical and biological methods are being used however, chemical method is most preferred over other method due to complexity of this disease and broader host range of pathogen. In recent years, the incidence of bakanae disease is increasing season to season in the Punjab and Haryana. Development and application of proper management technique will become strong challenge in future in rice based cropping system in the various places of Punjab and Haryana.

\section{Introduction}

Rice is being major staple food which is feeding more than $60 \%$ of world's total population. It is cultivated over 163.2 million hectares globally, with an average production of 4.6 tons per hectare by the year 2015 and it is forecasted that global paddy production will be increased by $0.9 \%$ by the year 2017 [FAO, 2015]. In India, the total area under rice cultivation was $43 \mathrm{mha}$ with the total production of 104.32 million tons during the year 2016-17. The expected production during the year 2016-17 was 109.15 million tons [Directorate of Economics and statistics, Commodity profile for rice, 2017]. It has been forecasted that, India needs to produce 113.3 $\mathrm{mt}$ rice to feed the increasing population by the year 2021 (Kumar, 2009). This demand will have to be supplied from less land, with less water, less labor and fewer chemicals. Rice being affected by various insects, pests, fungi, bacteria and nematodes are the major factors behind the yield instability. Roughly 
yield losses due insects, pests, pathogens, responsible for losses ranging between 20$40 \%$ of global agricultural production (Oerke 2006). To meet food demand of the world, Production has to be increased by adopting various improve agronomic practices, improved varieties, integrated diseases and pest management techniques

The "bakanae" is derived from Japanese word which means "Foolish". Bakane disease also known as "Foolish seedling disease" is come out as a seriously important disease in rice growing country in Asia. The disease incidence has increased in regular manner especially in the northern and central gangnetic plane zones of India which causes several qualitative and quantitative losses in yield of the paddy. The causative agent of this disease is fungus "Fusarium fujikuroi" Nirenberg [F. moniliforme (Sheld.), sexual stage: Gibberella fujikuroi Sawada, Wollenweber]. Crop losses due to this disease may reach up to $20 \%$ in outbreak cases. In India losses of $15 \%$ were reported [IRRI]. The incidence of this disease was reported high from the Punjab, Haryana, Uttar Pradesh and Uttarakhand (Bashyal et al., 2016). This disease is seed borne and soil borne which can survive for many years by forming resting spores during dormant period and becomes active when conditions are favorable. The disease incidence is very high on the variety Pusa Basmati 1121 and Pusa Basmati 1509 which is being growing throughout the country especially in Punjab and Haryana due to its grain quality. The incidence of this disease is also seen in other popular varieties including Pusa Basmati 6, CSR 30, Pusa Basmati 2511 and sarbati with the incidence $0.5 \%$ to $10 \%$ in the northern region of India including Punjab and Haryana. It was reported that approximately $24 \%$ of seed of Pusa Basmati were infected by Fusarium species of Gibberella fujikuroi complex (GFC) (Bashyal and Aggarwal, 2013).

\section{Causes}

The symptoms of bakane were first reported by Shotaro Hori in the year 1898 but disease was identified way back during 1828 in Japan. Hori demonstrated the fungus Fusarium heterosporium, during same year Nees illustrated the characterstic symptoms of bakane in rice plants.) (Ito and Kimura, 1931) put the pathogen in the genus Gibberella and named as Gibberella fujikuroi (Sawada). In the year 1917, Sawada showed that the rice seedlings elongation might be due to the production of some secondary metabolites by the hyphae of bakane fungus. Kurosawa (1926) manifested the overgrowth and elongation effect from culture filtrate of dried rice seedlings. Yabuta and Sumuki (1938) extracted gibberellins hormone in crystalline form from the pathogen Gibberella fujikuroi. They named the hormone as gibberellins because it was extracted from the fungus Gibberella. Today 72 forms of gibberellins are known, out of which 15 have been isolated from the fungus gibberella itself which is major cause of this disease especially in Asian countries which includes Japan (20$50 \%$ losses), Thailand (3.7-14\% losses), Bangladesh (25\% losses), Nepal (40\% losses), Pakistan (10-50\% losses).

Six biological species of Fusarium monliformae that share common sexual stage Gibberella fujikuroi, among six biological species (mating population) strains of A and D biological species contains two hormones fumonisin and mycotoxins. Desjardins et al., (1997) investigated the potential for mycotoxin contamination in rice pants infected by Fusarium species. They isolate Fusarium species from the samples of rice seeds. The results shows that pathogen present at husks of the seed were species of Gibberella fujikuroi complex including $G$. fujikuroi mating population A (asexual stage, Fusarium verticilliodes), G. fujikuroi mating population C (asexual stage, Fusarium 
fujikuroi) and G. fujikuroi mating population D (asexual stage, Fusarium proliferatum). This research also proofed those strains of mating population $\mathrm{A}$ and strains of mating population D fumonisin, beauvericin and usually monliformin with no gibberellic acids whereas strains of mating population $\mathrm{C}$ produced monliformin, beauvericin and gibberellic acid, but less or no fumonisin. They finally concluded that the gibberellin producing species $G$. fujikuroi mating population $\mathrm{C}$ is commonly associated with bakanae diseases of rice whereas mating population $\mathrm{D}$ is responsible for producing complex symptoms of bakanae. Wulff et al., (2010) also isolate the G. fujikuroi complex from the seeds of the rice plants infected by bakanae disease from African and Asian populations of Fusarium species with respect to their ecology, phylogenetics, mycotoxins production and pathogenicity. They found that four species of Fusaria ( $F$. andiyazi, $F$. fujikuroi, $F$. proliferatum and $F$. verticillioides) were associated with Bakanae of rice. While three of the Fusaria species were found in both African and Asian seed samples, F. fujikuroi was only detected in seed samples from Asia. The ability to produce fumonisins (FB1 and FB2) and gibberellins A3 in vitro also differed according to the Fusarium species. While fumonisins were produced by most of the strains of $F$. verticillioides and $F$. proliferatum, gibberellin A3 was only produced by $F$. fujikuroi. Neither fumonisin nor gibberellin was synthesized by most of the strains of $F$. andiyazi.

\section{Pathogen}

The causative agent of this disease Fusarium monliforme (sexual stage: Gibberella fujikuroi) belongs to kingdom Mycota, Division Eumycota and class Ascomycotina. Pathogen produce both sexual as well as asexual spores, sexual spores are ascospores that formed within a sac called as ascus. They are piston shaped, cylindrical, flattened and are 90-102 x 7-9 $\mu \mathrm{m}$ in size. Pathogen produce two types of asexual spores i.e. macro conidia and micro conidia. Microconidia are hyaline, single celled and oval. Whereas macroconidia are slightly sickle shaped and two to five cell. During dormant season pathogen survives by producing sclerotia having dark blue colour and spherical in shaped. The sclerotia are $80 \mathrm{x}$ $100 \mu \mathrm{m}$ in size.

\section{Symptoms}

The symptoms of this disease can occur at any stages of plant growing period. When the plant is infected by more than one species of Fusarium, they show complex symptoms. These complex symptom includes root rot, seedling blight, crown rot, stunting, weakening, overgrowth or excessive elongation of infected plants, foot rot, seedlings rot, infertile grains, grain discoloration which result in the reduction in yield and seed quality have been reported from various part of the world (Snyder and Hansen 1945; 1981, Sun 1975, Ou, 1985; Webster and Gunnell, 1992; Desjardins et al., 2000). Symptoms of these diseases also appear during its vegetative growth. During these period plants height increases to several inches taller than the normal plants. The infected plants shows early flowering due to the production of gibberellic acid. Formation of adventitious roots in the lower nodes has been reported from India and this disease is also described as Foot rot (Thomas, 1931). During the maturity period of the plant, infected plant show tall and thin tillers bearing pale-green flag leaves with less number of tillers and die within a few weeks due to drying of leaves. Occasionally, infected plants survive until maturity but don't bear any grains inside panicles. On the lower parts of the dying plants whitish or 
pinkish growth of the fungus may be observed. In Japan, panicles are often infected; these are referred to as pink panicles, caused by Fusarium roseum.

\section{Host range /favorable condition of pathogen}

The pathogen associated with this disease has very wide host range. The pathogen completes it sexual cycle in its primary host viz. rice, maize, barley, sorghum, sugarcane, wheat, pine, rye from Asia, Africa, South East Asia and United States has been reported (Kuhlman, 1982; Puhalla and Spieth, 1985; Wulff et al., 2010; Petrovic et al., 2013). Under unfavorable conditions pathogen survive in primary host, and spends remaining time in its alternate host. Cowpea Tomato, banana, proso millet, early water grass and barnyard grass have been found susceptible to bakanae disease of rice and may act as a alternate host (Anderson and Webster, 2005; Carter et al., 2008). The pathogen also survives in several hosts like round gourd, cucumber, Fig, Pine, Musa (Banana), cotton, sapodilla and leucaena during unfavorable condition.

Wollenweber and Reinking (1935) stated that fungus survives for 3 years in dry condition. Mandal and Chaudhari (1988) stated the $F$. monliformae survive for 210 days in soil. Soil moisture of $12.6 \%$ was found more favorable to survival than dry $(4.8 \%)$ or wet $(48 \%)$ condition. In field, nursery box seedlings are more susceptible to bakane than that of seedlings from protected nursery. The disease development relies on the seed selection, varieties and plant population. The disease incidence is more in the rice varieties viz. Basmati-1121 (Pusa-1121), CSR 30 and Taraori in the region of Haryana and Punjab. Disease incidences were reported more from high density planting area.

\section{Disease management}

Various methods were adopted for controlling Bakanae disease however farmers are using chemical method to control this disease in indo-gangetic plain zone including Haryana and Punjab. The following practices can be done to prevent the attack of this disease.

\section{Physical methods}

Ochi et al., (2016) suggested that contaminate rice seeds irradiated with atmospheric plasma containing electrons which have antimicrobial effect can be used to control this disease. Contaminated seeds after irradiated are wash with sterile distilled water, which results in the reduction of disease severity index and the percentage of infected plant $18.1 \%$ and $7.8 \%$ as compared to non-irradiated control with no effect in germination of seeds and seedling growth. Kang et al., (2016) reported the effect of soluble silicate clays zeolite dressing of the seed to control bakanae disease of rice. Their investigation concluded that seed dressing with the mixture of $25 \%$ silicic acid (act as a binder) and the zeolite (act as a coating powder) show the ratio of infected tiller not more than $0.01 \%$ whereas the ratio of infected tiller was $9.9 \%$ in non silicate coated seeds plot from mid tillering to heading stage. Soil solarization is another method which can reduce the disease incidence. Trapping the solar energy with the help of translucent polythene sheet to raise the temperature of soil (10-15 degree above the normal temperature) is enough to kill all the soil borne pathogen and weeds which acts as a host for pathogen. Hot water treatment is considered as one of the wide method to control seed borne pathogen. Kusakari et al., (2004) reported that sterilization of infected seeds with heated acidic electrolyzed water at $50^{\circ} \mathrm{C}$ for about $10-20$ minutes can minimize the infestation of this disease. 


\section{Biological methods}

Several fungus and some strains of bacteria has been found effective to suppress the mycelia growth, formation of asexual spores i.e. conidia and germination of fungus $F$. fujikuroi. Sarwar et al., (2018) investigated that Surfactin A purified from bacillus $\mathrm{NH}$ 100 and NH 217 can be use as a biocontrol agent to control rice bakane disease. Surfactin A minimizes the rice bakanae by 80 per cent and retains maximum antifungal activity at different $\mathrm{pH}$ (5 to 9) and temperature (20, 50 and 121 degree celcius). Hossain et al., (2016) reported that induction of strain YC7007 of bacterium Bacillus oryzicola can be applied as a biocontrol agent for controlling bakanae of rice. Drenching of roots with the suspension of bacterium strain YC7007 $(2.0 \times 107 \mathrm{cfu} / \mathrm{ml})$ to the rhizosphere of roots reduced bakanae extremity by 46 $78 \%$ in pots and nursery box tests containing sterile and not-sterile soils. Their study further revealed that spraying the culture filtrate of $B$. oryzicola YC7007 inhibit the occurrence of necrotic lesion and mycelial growth of fungus Fusarium fujikuroi. Seed disinfection with outer seed coat extract of Ginkgo biloba can retard the growth of Fusarium fujikuroi at $60 \%$ or more when applied concentration is 4000mg per L (Tae et al., 2016). Talaromyces spp. isolate KNB-422 obtained from the rice seedlings have microparasitic property and have ability to suppress the development of Gibberella fujikuroi as reported by Kato et al., (2012). Miyake et al., (2012) demonstrated the mechanism of action of KNB-422, which is isolated from rice seedlings; it grows the hyphae around the hyphae of pathogen and then perforated the hyphae of Gibberella fujikuroi and parasitizes the pathogen and prevents the growth. According to Kumar et al (2009), application of extracts of bacterial agents Pseudomonas fluorescens isolates PF9 and PF-13 and Bacillus thuringiensis isolates B-44 acts as an antagonist and produced lytic enzymes, siderophores, salicylic acid and HCN which minimize growth and development of the pathogen.

\section{Chemical methods}

This method is most followed method to control bakanae disease. When the population of fungus is too high, then chemical method is the only option. Various scientists suggested various chemical methods for controlling this disease.

Li et al., (2018) reported that use of phenamacril and ipconazole individually and in mixture can reduce the disease incidence. Their study concluded that application of phenamacril at the concentration of 0.1544 $\mu \mathrm{g} / \mathrm{ml}$ and ipconazole at the concentration of $0.0472 \mu \mathrm{g} / \mathrm{ml}$. EC50 show high antifungal activity against Fusarium fujikuroi mycelial growth when they are applied individually. When phenamacril and ipconazole were applied by mixing in the ratio of $2: 1$, it caused synergistic inhibition of mycelial growth of pathogen. Inhibition of $F$. fujikuroi sporulation was highest for ipconazole alone, intermediate with the 2:1 mixture, and lowest for phenamacril alone. Bal et al., (2018) reported that treatment of seeds with Bavistin 50 WP @ $0.2 \%$ followed by seedling dip treatment in Bavistin 50 WP @ 0.2\% and pulling up the infected seedlings in the nursery can control the disease $(92.2 \%)$ in the field; this whole process is considered as a most effective method to control foot rot of rice. Application of two chelating agent chitosan oligosaccharides (COS) and ethylene diamine tetraacetatic acid (EDTA) can be used to control bakanae of rice as COS exhibited fungicidal effect on hyphal growing cell within 5 minutes where EDTA had fungistatic effect on growth inhibition Kim et al., (2016).

Sundar et al., (2014) investigated that treatment of seed and seed soaking with 
carbendazim at $1-2 \mathrm{gm} / \mathrm{kg}$ of seed could minimize the disease incidence. Uprooting of paddy nursery in the standing water can reduce the incidence of this disease drastically as compared to uprooting of paddy nursery in vattar condition. Sand mix application of carbendazim in addition to treatment of seed in nursery beds at the rate of $1 \mathrm{gm} / \mathrm{m} 2$ before 7 days of uprooting seedlings followed by seedling dip in $0.1 \%$ carbendazim solution for 3 hours prior to transplanting reduced the incidence of bakane in transplanted rice. Application of carbendazim during flowering stage through foliar application minimizes the grain infection of Fusarium moniliforme from from $73.9 \%$ to $35.0 \%$.

Hossain et al., (2015) evaluated the effect of fungicides in in-vitro conditions; they tested the effects of 15 fungicides on infected plants. Among the 15 fungicides tested in vitro, all of them were found effective in various degrees against the pathogen of the disease. They concluded that following fungicides were most effective. Carbendazim (50\% WP) was the most effective followed by folicur $(25 \%$ Tebuconazole EC), protaf (25\% Propiconazole EC) and celest extra $(2.5 \%$ Fludioxonil and 2.5\% Difenoconazole EC). Seed treatment with Fungicides viz. thiram, benomyl, benomyl + thiram, carbendazim + thiram, carboxin + thiram, fludioxonil, mancozeb, iprodione + triticonazole, prochloraz, thiophanate - methyl and ipconazole at 1-2 per cent of seed weight found effective in various countries viz., Japan, Taiwan, Korea, Turkey, Iran, Pakistan, Bangladesh, India, Nepal and Italy (Bagga and Sharma, 2006; Bagga et al., 2007; Karov et al., 2009; Ghazanfar et al., 2009, Ora et al., 2011).

\section{References}

Anderson, L.L., and R.K. Webster .2005. A comparison of assays for Gibberella fujikuroi and their ability to predict resulting bakanae from seed sources in California. Phytopath. 95(4): 6.

Bagga, P.S., and V.K. Sharma. 2006. Evaluation of fungicides as seedling treatment for controlling bakanae/foodrot (Fusarium moniliforme) disease in basmati rice. J. Mycol. Pl. Pathol. 59: 305-308.

Bagga, P.S., V.K. Sharma, and P.P.S. Pannu. 2007. Effect of transplanting dates and chemical seed treatments on foot rot disease of basmati rice caused by $F$. moniliforme. Pl. Dis. Res. 22: 60- 62.

Bal RS., and Barun Biswas.2018. Epidemiology and Management of Foot Rot in Basmati Rice; J Krishi Vigyan; PAU's Regional Research Station, Gurdaspur -143521(Punjab) 6(2): 87-94.

Bishnu Bashyal and Rashmi Aggarwal. 2013. Molecular identification of Fusarium species associated with bakanae disease of rice (Oryza sativa) in India. Indian Journal of Agricultural Sciences 83(1): 71-76.

Bishnu Bashyal, Rashmi Aggarwal, Sapna Sharma and S. Gopala Krishnan. 2016. Occurrence, identification and pathogenicity of Fusarium species associated with bakanae disease of basmati rice in India. European Journal of Plant Pathology; 144(2)

Carter, L.L.A., F.J. Leslie, and R.K. Webster (2008). Population structure of Fusarium fujikuroi from California rice and water grass. Phytopathol. 98: 99299

Desjardins, A.E., H.K. Manandhar, R.D. Plattner, G.G. Manandhar, S.M. Poling, and C.M. Maragos. 2000. Fusarium species from Nepalese rice and production of mycotoxins and gibberellic acid by selected species. Appl. and Environ. Microbiol. 66: 10201025

Desjardins, A.E., R.D. Plattner and Nelson, 
P.E. 1997. Production of fumonisin B1 and moniliformin by Gibberella fujikuroi from rice from various geographic areas. Appl. Environ. Microbiol. 63: 1838-1842

Directorate of Economics and statistics, Commodity profile for rice, 2017

FAO. 2017. Rice Market Monitor, Rome, Italy. Global Rice Market summary, volume xx Issue no. I.

Ghazanfar, M.U., W. Wakil, M. Iqbal, and A. Ahmad. 2009. Impact of various fungicides against bakanae disease of rice under the field conditions. 5th International Conference on Plant Pathology in the Globalized Era, Nov. 10- 13, New Delhi, (India).

Hossain KS., M A Taher Mia. 2015. Management of bakanae disease of rice; Bangladesh Journal of Botany 44(2): 277-283.

Hossain MT., Ajmal Khan, Eu Jin Chung, Md. Harun-Or Rashid, and Young Ryun Chung. 2016. Biological Control of Rice Bakanae by an Endophytic Bacillus oryzicola YC7007; Korean society of plant pathology 32(3): 228-241.

Ito, S., and J. Kimura. 1931. Studies on the bakanae disease of the rice plant. Rep. Hokkaido Agric. Exp. Stn. 27: 1-95.

Kang, Yang-Soon; Kim, Wan Joong; Kim, Yeon Ju; Jung, Ki-Hong; Choi, Ul-Su. 2016. Bakanae Disease Reduction Effect by Use of Silicate Coated Seed in Wet Direct-Seeded Rice. Korean journal of crop science 61(1): 9-16.

Karov, I.K., K. Mitrev, Sasa, and D.K. Emilija (2009). Gibberella fujikuroi (Sawada) Wollenweber- the new parasitical fungus on rice in the republic of Macedonia. Proc. Nat. Sci. Matica Srpska Novi Sad. 116: 175-182.

Kato, A., M. Taiji, N. Kana, T. Hideaki, T. Tohru. 2012. Visualize interactions between the Bakanae disease pathogen Gibberella fujikuroi and the agent
Talaromyces $s p$ KNB-422. Journal of General Plant Pathology, 78(1): 54-61

Kuhlman, E.G., 1982. Varieties of Gibberella fujikuroi with anamorphs in Fusarium section Liseola. Mycologia. 74: 759768.

Kumar P., PK. Joshi, Pratap S. Birthal. 2009. Demand Projections for Foodgrains in India . Agricultural Economics Research Review $22: 237-243$

Kurosawa, E., 1926. Experimental studies on the nature of the substance secreted by the bakanae fungus. Nat. Hist. Soc. Formosa. 16: 213-227.

Kusakari, S., Achiwa, N. Abe, K. 2004. Control of bakanae disease by soaking seed in heated electrolyzed acid water (EAW) under field conditions.

Li Meixia, Tao Li, Yabing Duan, Ying Yang, Jian $\mathrm{Wu}$, Donglei Zhao, Xue mei Xiao, Xiayan Pan, Weiwei Chen, Jianxin Wang, Changjun Chen and Mingguo Zhou. 2018. Evaluation of Phenamacril and Ipconazole for Control of rice Bakanae Disease Caused by Fusarium fujikuroi; The American phytopathological society Volume 102(7): 1234-1239.

Mandal, D.N., and S. Chaudhuri. 1988. Survivality of Fusarium moniliforme Sheld. under different moisture regimes and soil conditions. Int. J. Trop. Pl. Dis. 6: 201-206.

Miyake T., Akihiro Kato; Hideaki Tateishi; Tsutomu Arie. 2012. Mode of action of Talaromyces sp. KNB422, A biocontrol agent against rice seedling diseases. Journal of Pesticide Science 37(1):56-61

Ochi A., H. Konishi, S. Ando, K. Sato, K. Yokoyama, S. Tsushima, S. Yoshida, T. Morikawa,T. Kaneko, H. Takahashi. 2016. Management of bakanae and bacterial seedling blight diseases in nurseries by irradiating rice seeds with atmospheric plasma. British society of plant pathology. 
Oerke. EC., 2006. Crop losses to pests. Journal of Agricultural Science, 144, $31-43$.

Ora, N., A.N., Faruq, M.T. Islam, N. Akhtar, and M.M. Rahman. 2011. Detection and identification of seed borne pathogens from some cultivated hybrid rice varieties in Bangladesh. Middle-East J. Scient. Res. 10: 482-488.

Ou, S.H., 1985. Rice Diseases. 2nd ed. Commonwealth Mycological Institute, Kew, Surrey, England, UK. pp.380.

Petrovic, T., L. Burgess, I. Cowie, R. Warren, and P. Harvey. 2013. Diversity and fertility of Fusarium sacchari from wild rice (Oryza australiensis) in Northern Australia, and pathogenicity tests with wild rice, rice, sorghum and maize. European J. Pl. Path. 136: 773-788.

Puhalla, J.E., and P.T. Spieth. 1985. A comparison of heterokaryosis and vegetative compatibility among varieties of Gibberella fujikurai (Fusarium monoliforme). Exp. Mycol. 9: 39-47

Sarwar Ambrin; Muhammad Nadeem Hassan; Muhammad Imran; Mazzar Iqbal; Saima Majeed. 2018. Biocontrol activity of surfactin A purified from Bacillus $\mathrm{NH}-100$ and $\mathrm{NH}-217$ against rice bakanae disease. Microbiological research 209: 1-13.

Seung Won Kim; Jae Kweon Park; Cho Heun Lee; Bum-Soo Hahn; Ja Choon Koo. 2016. Comparison of the Antimicrobial Properties of Chitosan Oligosaccharides (COS) and EDTA against Fusarium fujikuroi Causing Rice Bakanae Diseases. Current microbiology 72(4): 496-502.
Snyder, W.C., and H.N. Hansen. 1945. The species concept in Fusarium with reference to discolor and other sections. Am. J. Bot. 32: 657-666.

Sun, S.K. 1975. The diseases cycle of rice bakanae disease in Taiwan, Proc. Natl. Sci. Counc. Repub. China. 8: 245-256

Sunder S; Ram Singh; D S Dodan. 2014. Management of bakanae disease of rice caused by Fusarium moniliforme. Indian Journal of Agricultural Sciences 84 (1): $48-52$.

Tae seok oh, you jin park, chang ho kim, young koo cho, myoung jun jang. 2016. Effect of seed disinfection on bakanae disease in ginkgo biloba outer seed coat extract. Emirates journal of food and agriculture 28(9).

Thomas, K.M. 1931. A new paddy disease in Madras. Madras Agril. J. 19: 34-36

Webster, R.K., and P.S. Gunnell. 1992. Compendium of rice disease. First edition, The American Phytopathological Society Press. St. Paul, Minnesota, USA. pp: 86.

Wollenweber, H.W. and O.A. Reinking 1935. Dien Fusarien, ihre Beschreibung, Schadwirkung und Kekampfung. Berlin: Paul Parey. pp. 355.

Wulff, ED., J.L. Sorensen, M. Lubeck, K.F. Nelson, U. Thrane, and J. Torp. 2010. Fusarium spp. associated with rice bakanae: ecology, genetic diversity, pathogenicity abd toxigenicity. Envir. microbiol. 12: 649-657

Yabuta, T., and Y. Sumiki. 1938. On the crystal of gibberellin, a substance to promote plant growth. J. Agric. Chem. Soc. Japan. 14: 1526.

\section{How to cite this article:}

Pooja Katoch, Abhishek Katoch, Mahendra Paudel and Shristi Upreti. 2019. Bakanae of Rice: A Serious Disease in Punjab. Int.J.Curr.Microbiol.App.Sci. 8(05): 129-136. doi: https://doi.org/10.20546/ijcmas.2019.805.017 